\title{
Systemic concentrations of hormones during the development of follicular waves in mares and women: a comparative study
}

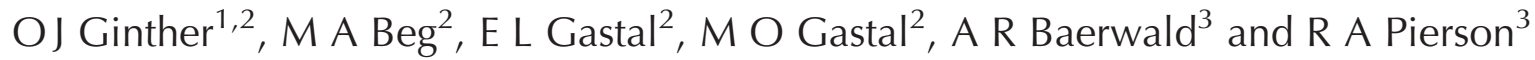 \\ ${ }^{1}$ Eutheria Foundation, Cross Plains, Wisconsin 53528, USA, ${ }^{2}$ Animal Health and Biomedical Sciences, University \\ of Wisconsin, Madison, Wisconsin 53706, USA and ${ }^{3}$ Women's Health Imaging Research Laboratory, Department \\ of Obstetrics, Gynecology, and Reproductive Sciences, College of Medicine, University of Saskatchewan, \\ Saskatoon, Saskatchewan S7N OW8, Canada
}

Correspondence should be addressed to O J Ginther, Animal Health and Biomedical Sciences, 1656 Linden Drive, University of Wisconsin, Madison, Wisconsin 53706, USA; Email: ginther@svm.vetmed.wisc.edu

\begin{abstract}
Changes in systemic concentrations of $\mathrm{FSH}$, $\mathrm{LH}$, oestradiol and progesterone during the ovulatory follicular wave were compared between 30 mares and 30 women. Based on a previous study, the emergence of the future ovulatory follicle was defined as occurring at $13.0 \mathrm{~mm}$ in mares and $6.0 \mathrm{~mm}$ in women, and deviation in diameter between the two largest follicles was expected to begin at $22.7 \mathrm{~mm}$ in mares and $10.3 \mathrm{~mm}$ in women. Mean FSH concentrations were high in mares during the luteal phase, resulting from statistically identified FSH surges occurring in individuals on different days and in different numbers (mean, $1.5 \pm 0.2$ surges/mare); the internadir interval was $3.9 \pm 0.3$ days. In contrast, mean FSH in women was low during the luteal phase and increased to a prolonged elevation during the follicular phase. The prolonged elevation was apparent in each individual (internadir interval, $15.2 \pm 0.4$ days). Changes in LH or oestradiol concentrations encompassing deviation were not detected in mares, but both hormones increased slightly but significantly between emergence and deviation in women. The hypothesis that a greater number of growing follicles causes a greater predeviation decrease in FSH was supported for mares $(r,-0.39 ; P<0.04)$, but a similar negative correlation $(r,-0.36)$ was not significant in women. The hypothesis that the increase in oestradiol during the luteal phase in women was at least partly attributable to luteal-phase anovulatory follicular waves was not supported. Normalization of FSH concentrations to the day of emergence showed maximum value on the day of emergence with a significant increase and decrease on each side of emergence in both species. The day of expected deviation occurred 3 days after emergence during the decline in FSH in both species. These results indicated that the previously reported striking similarities in emergence and deviation between mares and women during the ovulatory follicular wave are associated with species similarities in the temporal relationships between follicle events and FSH concentration changes. Thus, mares may be useful research models for studying the role and mechanism of the action of FSH in emergence and deviation during the ovulatory follicular wave in women.

Reproduction (2005) 130 379-388
\end{abstract}

\section{Introduction}

Horses (Ginther et al. 2004a) and humans (Baerwald et al. 2003, Ginther et al. 2004b) have an effective follicle selection mechanism, so that usually only one follicle of an ovulatory follicular wave becomes dominant and ovulates. Anovulatory follicular waves also occur in both species and are defined as major waves when a dominant follicle develops and minor waves when a dominant follicle does not develop. The eminent selection event during a major wave occurs at the end of a common growth phase and is characterized by deviation or a change in growth rates between the develop- ing dominant follicle and the remaining follicles (subordinates). The nature of ovulatory follicular waves was recently compared between 30 mares and 30 women (Ginther et al. 2004b). The diameter of the future dominant follicle at emergence (mares, $13.0 \mathrm{~mm}$; women, $6.0 \mathrm{~mm}$ ) and the required minimal attained diameter for assessment of follicles (mares, $17.0 \mathrm{~mm}$; women, $8.0 \mathrm{~mm}$ ) were chosen to simulate the ratio between the two species in reported mean diameter of the future dominant follicle (F1) at the beginning of deviation (mares, $22.5 \mathrm{~mm}$; women, $10.5 \mathrm{~mm}$ ). Within each species, the future largest subordinate follicle (F2) 
emerged after F1 and the growth rate for F1 and F2 during the common growth phase was similar. The length of the interval between the emergence of the two follicles, the length of the interval from emergence to deviation (3 days) and the percentage increase per day in follicle diameter during the common growth phase were similar between species. Proportionality between species in the diameter of F1 at deviation (2.2 times larger for mares than for women) and at maximum preovulatory diameter (2.1 times larger; 44.8 versus $21.8 \mathrm{~mm}$ ) indicated that the relative growth of F1 after deviation was also similar between species. The incidence of a major anovulatory wave preceding the ovulatory wave was not different between species (combined, 25\%). Similar follicle dynamics between mares and women have indicated that the mare may be a useful experimental model for the study of folliculogenesis in women.

The available information on the relationships of circulating gonadotrophins to various events during follicular waves has been reviewed for mares (Ginther et al. 2004a) and women (Zeleznik 2001, Fauser \& van Heusden 1997). In mares, the wave stimulating follicle-stimulating hormone $(\mathrm{FSH})$ surge reaches peak concentrations when the largest follicle is a mean of $13 \mathrm{~mm}$. Deviation begins while the concentrations of FSH are decreasing. The FSH decline is necessary for the establishment of deviation, as indicated by the development of several dominant follicles after administering FSH or an anti-inhibin. Between the peak of the FSH surge and the beginning of deviation all follicles of the wave contribute to the $\mathrm{FSH}$ decrease, as demonstrated by manipulating follicle numbers. Concentrations of FSH continue to decline after deviation and do not begin to increase until approximately the day of ovulation.

In women, the temporal associations between emergence or deviation and circulating concentrations of hormones have not been well defined, because of the lack of adequate information on associated follicle diameters. In a recent study (Baerwald et al. 2003), concentrations of FSH began to increase 2 or 3 days before the follicles of a wave were $\geq 4 \mathrm{~mm}$. In another study (van Santbrink et al. 1995), FSH concentrations were related to the day the largest follicle was a median of $11 \mathrm{~mm}$ (range, 9-15 mm) and was defined as a dominant follicle. Concentrations of FSH decreased for approximately 2 or 3 days before and after the diameter was attained. Deviation apparently occurred during the decline in the FSH surge. Although not studied critically in women, the available information suggests that an FSH surge is temporally associated with stimulation of follicular waves, with deviation occurring during the decline in the surge in both species. Similar follicle/FSH temporal relationships occur in cattle (Ginther et al. 2003).

Oestradiol and luteinizing hormone (LH) concentrations begin to increase in mares 1 or 2 days before deviation in experimentally induced waves (Ginther et al. 2004a), but the time of increase relative to deviation for natural waves is apparently not known. In cattle, LH and oestradiol in natural waves begin to increase before and at the beginning of deviation respectively (Ginther et al. 2003). In women, the relationship of oestradiol and LH concentrations to emergence and deviation has not been studied directly. In one study (van Santbrink et al. 1995), oestradiol increased on the first day a dominant follicle was distinguishable. In women (Baerwald et al. 2003), an increase in oestradiol occurs during the luteal phase, beginning after the periovulatory surge. This prolonged elevation in oestradiol is from luteal production, but luteal-phase follicular waves are a potential additional source that has not been investigated.

In mares, concentrations of the periovulatory LH surge begin to increase during the $\mathrm{FSH}$ decline, reach maximal concentrations the day after ovulation and then decline for several days (for review see Ginther 1992). Thus, LH and FSH are dissociated during the periovulatory period. In contrast, FSH and LH reach a peak simultaneously 1 day before ovulation in women (Reddi et al. 1990). Similar relationships between $\mathrm{FSH}$ and $\mathrm{LH}$ peaks on the day before ovulation occur in cattle (Haughian et al. 2004). The periovulatory oestradiol peak occurs 1 or 2 days before ovulation in mares or 2 or 3 days before the LH peak (Ginther 1992). In women, the oestradiol peak occurs 2 days before ovulation or 1 day before the LH peak (Reddi et al. 1990). Progesterone concentrations begin to increase near ovulation in both mares (Ginther 1992) and women (Reddi et al. 1990). By 14 days after ovulation, concentrations have decreased to basal levels in women and are beginning to decrease in mares. In summary, the temporal relationships between $\mathrm{FSH}$ and $\mathrm{LH}$ during the periovulatory period are distinctly different between the two species, but the follicle characteristics earlier in the ovulatory wave are similar.

The purpose of this study was to compare and contrast, between mares and women, the characteristics of systemic hormone concentrations that are temporally associated with follicle emergence and deviation during the ovulatory wave. The following hypotheses were tested: (1) the increase in oestradiol during the luteal phase in women is at least partly attributable to lutealphase anovulatory follicular waves, (2) the peak of the wave-stimulating FSH surge occurs at emergence in both species, using the previously derived common definition of diameter of the future ovulatory follicle at emergence (mares, $13.0 \mathrm{~mm}$; women, $6.0 \mathrm{~mm}$; Ginther et al. 2004b), (3) an increase in LH and oestradiol occurs before follicle deviation in both species and (4) the concentration of FSH near the end of the common growth phase is inversely related to the number of growing follicles in both species. In addition, the differences between species in the temporal relationships among concentrations of $\mathrm{FSH}, \mathrm{LH}$, oestradiol and progesterone during the periovulatory period are illustrated. 


\section{Materials and Methods}

\section{Mares}

Mares were managed according to the Guide for the Care and Use of Agricultural Animals in Agricultural Research and Teaching (Ginther et al. 2004b). Data were obtained from 30 mares during the October-March ovulatory season in Brazil (latitude, $21^{\circ} \mathrm{S}$ ). Non-pregnant, non-lactating, small draft-type, crossbred Breton mares between 3 and 13 years of age and weighing $390-550 \mathrm{~kg}$ were used. Mares were kept on pasture under natural light. Blood samples were collected daily, and assays were done for samples collected from 4 days before the first ovulation (day 0) of an interovulatory interval to 4 days after the second ovulation. The results of follicle analyses for these 30 interovulatory intervals have been reported (Ginther et al. 2004b) but not the results of hormone assays.

\section{Women}

The protocol was approved by the Institutional Review Board of the University of Saskatchewan (Baerwald et al. 2003). Informed consent was obtained from all women prior to initiating study procedures. Thirty women were used so that the number of individuals was consistent for women and mares. The interovulatory intervals were the same as those used previously for species comparisons of the dynamics of follicular waves (Ginther et al. 2004b). The women were non-pregnant, non-lactating and were 19-43 years of age; the selection criteria have been described (Baerwald et al. 2003). Results for concentrations of $\mathrm{FSH}, \mathrm{LH}$, oestradiol (Baerwald et al. 2003) and progesterone (Baerwald et al. 2005) have been reported in comparisons between interovulatory intervals with various combinations of major and minor follicular waves. However, the temporal relationships among $\mathrm{LH}$, oestradiol and progesterone concentrations and follicle events during the wave have not been reported. Duplication of the previously reported findings in the present study was minimal. Unlike the daily blood samples in mares, samples for women were available only for every third day. The sampling in individuals began before the first ovulation of the experimental interovulatory interval and extended until 3 days after the second ovulation. Because of the 3 day sampling interval, the samples were not synchronized among individuals relative to the daily assessed follicle events (i.e. emergence, deviation). However, a sample was available from each woman from either the day before, the day of, or the day after a follicle event. To consider hormone data normalized to emergence and deviation, sequential 3-day sets were therefore used, so that a set encompassed the day of the event (e.g. day of emergence \pm 1 day; $n=30$ women/set). In addition to this conservative approach, which provided data for all women in each set, the values were also assessed on a daily basis relative to deviation. With the latter approach, only one-third of women were available for each day.

\section{Follicles}

The present study includes three mares and five women that were not included in the previous detailed comparative follicle analyses (Ginther et al. 2004b). Preliminary study indicated that inclusion of the additional individuals did not alter the hormone profiles. Emergence was defined as the day the future ovulatory follicle was closest to $13.0 \mathrm{~mm}$ (mares) and $6.0 \mathrm{~mm}$ (women) on the basis of a constant diameter ratio between species at emergence, deviation and preovulation, as described (Ginther et al. $2004 b)$. In the previously excluded individuals, the observed day of deviation was not determinable, because of the absence of a clearly defined subordinate follicle. In the present study, the entire group of 30 individuals was used by defining the expected beginning of deviation as the day the future ovulatory follicle was closest to $22.7 \mathrm{~mm}$ (mares) and $10.3 \mathrm{~mm}$ (women). This was done on the basis of the reported mean diameter at observed deviation for the two species, as described for the previous study.

\section{Normalization}

Normalization to each of the two ovulations was used to provide a visual comparison between species of the temporal relationships between the follicular and hormonal events. Length of the interovulatory interval (mares, 21 days; women, 27 days) and mean days of emergence and deviation were considered in partitioning the data between the two ovulations. For normalization to the first ovulation, data extended from 4 days before ovulation to 10 days (mares) and 13 days (women) after ovulation. For the second ovulation, data extended from 10 days (mares) and 13 days (women) before ovulation to 4 days (mares) and 3 days (women) after ovulation. Hormone data for each day were used for women for preparation of the normalized graphs, even though hormone information for each individual was available for only every 3 days. This was done to provide a similar display for visual comparison between species.

Hypotheses on the relationship of changes in concentration of hormones relative to day of emergence or deviation were examined by centralizing to the day of defined emergence or defined deviation. In mares, FSH data preceding the nadir at the onset of the apparent wave-stimulating surge were not included. In individual women, the 3-day data set that encompassed the designated day was used. Also, the diameter of the future dominant follicle for major waves and the largest follicle for minor waves on the day of the peak of statistically identified FSH surges were determined in mares. A similar study was not done in women because of the 3-day interval between blood samples.

The hypothesis on the effect of number of growing follicles on FSH concentrations on the day before expected deviation was studied by correlation. The day before deviation was chosen on the basis of results of a study in 
which the number of follicles was altered experimentally (Donadeu \& Ginther 2001). To qualify as a growing follicle, an increase in diameter between 2 days to 1 day before deviation was required. In addition to the correlation, comparisons of $\mathrm{FSH}$ concentrations were made between groups with one or two versus three or more follicles. These combined groups were used to provide an adequate number of follicles in each group and because experimental manipulation of follicle numbers by ablation indicated that three or more follicles were needed for maximal FSH decrease in mares (Donadeu \& Ginther 2001) and cattle (Gibbons et al. 1997). The hypothesis on the differences in oestradiol concentrations during the luteal phase between women with and without anovulatory follicular waves was examined for the 3-day sets extending from 1 day to 15 days after the first ovulation. Only waves that began on or after ovulation and had a largest follicle that reached its maximum diameter during the 15 days were used.

\section{Blood samples and hormone assays}

In mares, daily jugular blood samples were collected into heparinized tubes and centrifuged $(1500 \mathrm{~g}$ for $10 \mathrm{~min})$ and plasma was decanted and stored $\left(-20^{\circ} \mathrm{C}\right)$ until assay. Plasma concentrations of $\mathrm{FSH}$ and $\mathrm{LH}$ were assayed for the daily blood samples for all 30 mares. Oestradiol and progesterone were assayed for the daily samples of 15 randomly selected mares. Plasma samples were assayed for FSH and LH by RIA as validated and described for mares (Donadeu \& Ginther 2002) in our laboratory. The intraand interassay coefficients of variation (CV) and mean sensitivity were respectively $13.7 \%, 5.8 \%$ and $1.4 \mathrm{ng} / \mathrm{ml}$ for $\mathrm{FSH}$ and $10.4 \%, 15.1 \%$ and $0.2 \mathrm{ng} / \mathrm{ml}$ for LH. Plasma concentrations of oestradiol were measured by a double-antibody RIA kit (double antibody estradiol; Diagnostic Products Corporation, Los Angeles, CA, USA) as described for mares (Gastal et al. 1999) with the following modifications. The standards $(100-0.78 \mathrm{pg} / \mathrm{ml})$ were prepared by serial dilution in steroid-free (charcoal-extracted) equine plasma. The standards and plasma samples $(400 \mu \mathrm{l})$ were extracted simultaneously with diethyl ether before the assay. The intra- and interassay CV values were $11.4 \%$ and $6.7 \%$ respectively and sensitivity was $0.4 \mathrm{pg} / \mathrm{ml}$. Plasma progesterone concentrations were determined using a solid-phase RIA kit containing antibody-coated tubes and ${ }^{125}$ I-labelled progesterone (Coat-A-Count; Diagnostic Products Corporation). The kit-supplied standards $(40-0.1 \mathrm{ng} / \mathrm{ml})$ and unknown plasma samples were pipetted $(100 \mu \mathrm{l})$ into antibody-coated tubes. Progesterone tracer $(1 \mathrm{ml})$ was added to each tube and the tubes were vortexed and incubated for $3 \mathrm{~h}$ at room temperature. The tubes were decanted, thoroughly drained and counted for $1 \mathrm{~min}$ in a gamma counter. Serial volumes of a pool of dioestrous mare plasma $(50-300 \mu \mathrm{l})$ were processed as for the unknown samples and resulted in a displacement curve that was similar to the standard curve. The intra- and interassay $\mathrm{CV}$ values were $3.4 \%$ and $6.4 \%$ respectively and the sensitivity was $0.04 \mathrm{ng} / \mathrm{ml}$.

The assay methodology for the samples from women has been reported previously for $\mathrm{FSH}, \mathrm{LH}$ and oestradiol (Baerwald et al. 2003) and for progesterone (Baerwald et al. 2005). Briefly, serum was stored at $-20^{\circ} \mathrm{C}$ and sequential competitive fluorescence immunoassays were used. Interassay $\mathrm{CV}$ values were as follows: $\mathrm{FSH} \quad($ low $=8.0 \%$, medium $=2.9 \%$, high $=4.1 \%), \quad \mathrm{LH}$ (low $=6.3 \%$, medium $=4.0 \%$, high $=4.5 \%$, oestradiol (low $=9.8 \%$, medium $=5.6 \%$, high $=4.3 \%$ ) and progesterone (low $=10.8 \%$, medium $=7.0 \%$, high $=10.8 \%$ ). Sensitivities were $0.1 \mathrm{mlU} / \mathrm{ml}$ for $\mathrm{FSH}, 0.1 \mathrm{mlU} / \mathrm{ml}$ for $\mathrm{LH}, 15 \mathrm{pg} / \mathrm{ml}$ for oestradiol and $0.2 \mathrm{ng} / \mathrm{ml}$ for progesterone.

\section{Statistical analyses}

The changes in concentrations of a hormone relative to emergence and deviation were examined, using the MIXED procedure of SAS with a repeated measure statement and a first order autoregressive structure to account for the autocorrelation between measurements (version 8.2; SAS Institute Inc., Cary, NC, USA). When a significant $(P<0.05)$ day effect was obtained, differences between days of emergence versus a preceding day and emergence versus a following day were examined with Student's paired t-tests. Surges in daily circulating concentrations of FSH within each mare were differentiated from variation due to extraneous factors (variation in sampling or assaying technique), as described (Fitzgerald et al. 1985) in mares. The $\mathrm{CV}$ of the values composing the ascending and descending portions of the suspected surge had to be at least two times higher (Lin \& Lee 1998) than the mean intra-assay CV. In addition, a given surge had to include values from at least 3 days. The highest value associated with an identified surge was defined as a peak. The diameter of the future dominant follicle on the day of the FSH peak was compared between the ovulatory wave and anovulatory waves by one-way ANOVA. Statistical identification of FSH surges was not done in women because of the 3-day interval between samples. Differences in oestradiol concentrations during the luteal phase were examined for main effects of group (anovulatory waves and no waves) and day and interaction, using the MIXED procedure of SAS. No differences were found between major and minor anovulatory waves and the two groups were combined. A main effect of day was further examined as described above. Pearson correlation and ANOVA of follicle-number groups were used to examine the effect of the number of follicles on FSH concentrations on the day before the expected beginning of deviation. A probability of $P \leq 0.05$ indicated that a difference was significant and $P>0.05$ to $\leq 0.1$ indicated that a difference approached significance. Data are presented as the means \pm S.E.M. unless otherwise indicated. 


\section{Results}

The overview of hormone changes and follicle events normalized to the first and second ovulations of the interovulatory interval is shown for mares (Fig. 1) and women (Fig. 2). The changing concentrations of FSH, LH, oestradiol and progesterone and the diameter of the dominant follicle are depicted. Examples of the FSH and follicle relationships are shown for interovulatory intervals for two individual mares and two women with one and multiple follicular waves (Fig. 3).

In mares, emergence of the future dominant follicle at a diameter closest to $13.0 \mathrm{~mm}$ occurred on day $8.1 \pm 0.7$ and ranged from day 1 to day 14 ; the variance was greater $(P<0.005)$ in mares $( \pm 15.1$ days $)$ than in women $( \pm 6.2$ days). For the 15 progesterone-assayed mares, emergence occurred during the luteal phase in $57 \%$, using a decrease in progesterone to $<1.0 \mathrm{ng} / \mathrm{ml}$ to indicate the end of the luteal phase. The number of statistically identified FSH surges during the interovulatory interval was $1.5 \pm 0.2$. A statistically defined surge was temporally associated with emergence of the ovulatory wave in $80 \%$ of mares; the $20 \%$ (six mares) without an associated surge included three mares without a detected surge during the interovulatory interval. Multiple surges occurred in $50 \%$ of interovulatory intervals, and no surges were detected in $10 \%$. Length of the nadir-to-nadir interval encompassing an identified surge was $3.9 \pm 0.3$ days. In women, follicle emergence at a diameter closest to $6.0 \mathrm{~mm}$ occurred after

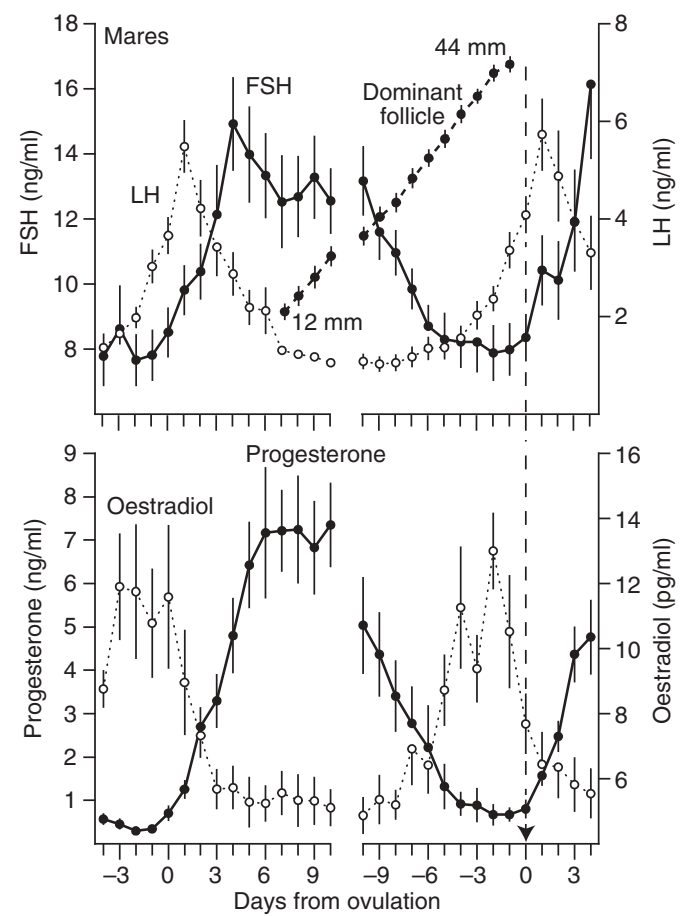

Figure 1 Mean \pm S.E.M. values showing the temporal associations among circulating concentrations of FSH and $\mathrm{LH}(n=30)$ and oestradiol and progesterone $(n=15)$ and growth of the dominant follicle of the ovulatory follicular wave in mares.

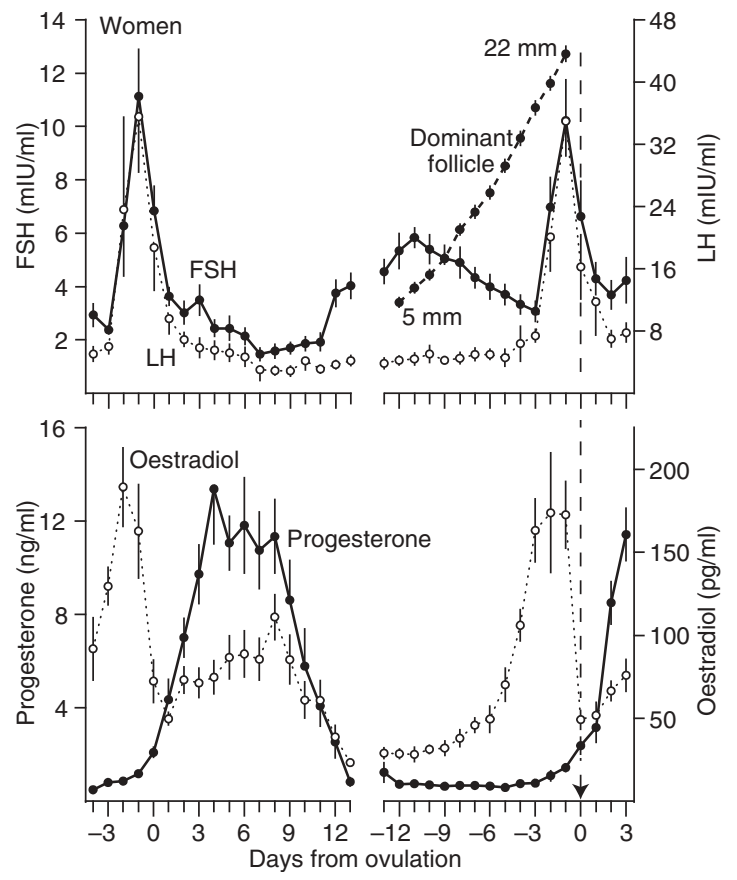

Figure 2 Mean \pm S.E.M. values showing the temporal associations among circulating concentrations of $\mathrm{FSH}, \mathrm{LH}$, oestradiol and progesterone and growth of the dominant follicle of the ovulatory follicular wave in 30 women.

progesterone had decreased to minimal concentrations or during the follicular phase in all women (mean, day $16.3 \pm 0.5)$. The concentration of FSH on the day of emergence $(6.1 \pm 0.6 \mathrm{mlU} / \mathrm{ml} ; n=10)$ was $60 \%$ of the concentration on the day before the second ovulation $(10.2 \pm 1.3 \mathrm{mlU} / \mathrm{ml})$ in women with a blood sample on the indicated days.

The day effect for concentrations of FSH normalized to emergence of the future dominant follicle was significant $(P<0.0001)$ for mares (Fig. 4) and women (Fig. 5). In both species, FSH concentrations were highest at emergence, with significant changes on each side of emergence. The diameter of the largest follicle at the peak of identified FSH surges in mares was not significantly different between the ovulatory wave $(13.5 \pm 0.5 \mathrm{~mm})$ and combined minor and major anovulatory waves $(14.2 \pm 0.5 \mathrm{~mm})$. The interval from emergence to the beginning of deviation was not significantly different between mares $(3.1 \pm 0.2$ days) and women (3.4 \pm 0.2 days). In both species, concentrations of FSH decreased significantly before and after expected deviation when data were normalized to deviation (not shown).

In mares, the day effect for $\mathrm{LH}$ was significant $(P<0.006$; Fig. 4). Concentrations decreased before and after emergence and did not increase before deviation. No changes in oestradiol or progesterone were detected, encompassing emergence and deviation (Fig. 4). In women, using the 3-day sets, the day effect was significant for $\mathrm{LH}(P<0.02)$ and for oestradiol and progesterone 


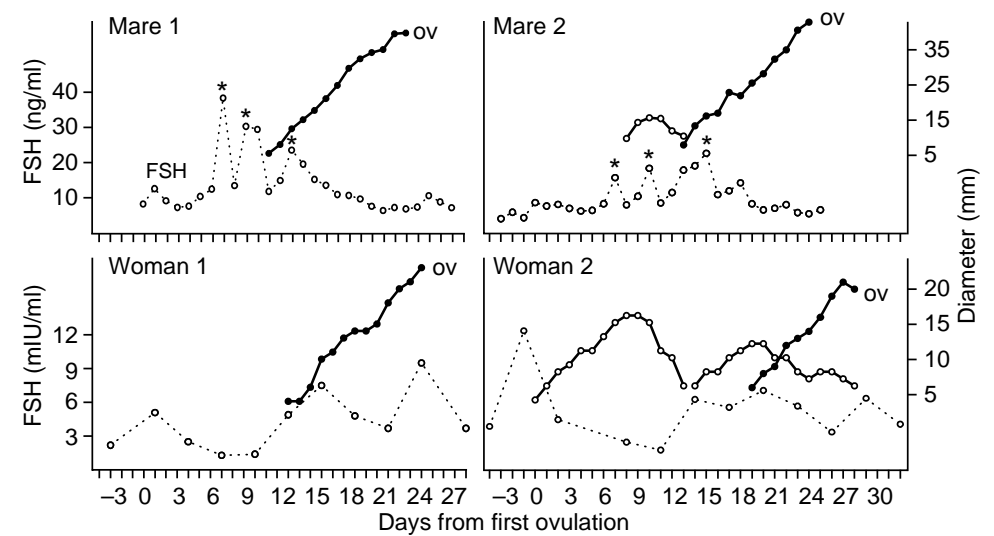

Figure 3 Concentrations of FSH and diameters of the ovulatory follicle (left panels) and the diameters of ovulatory and anovulatory follicles (right panels) in two individuals of each species. An asterisk designates the peak of a statistically identified FSH surge in mares. ov, ovulation.

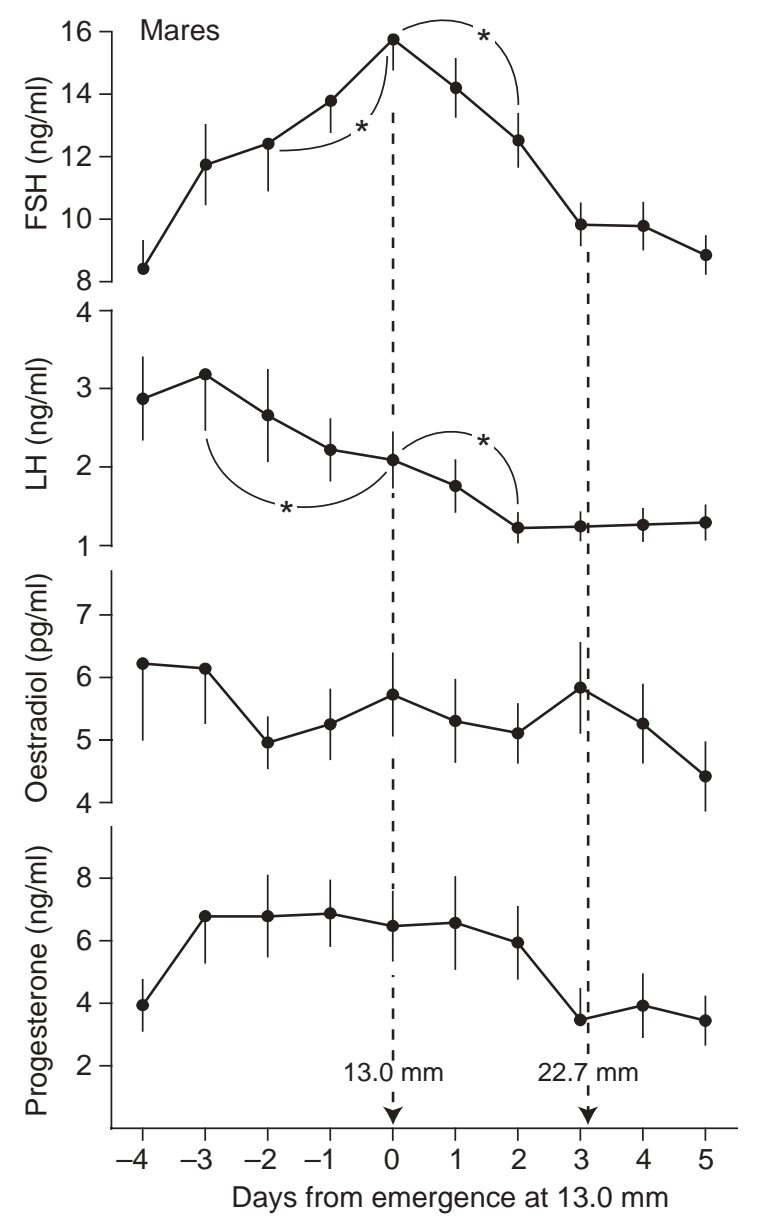

Figure 4 Mean \pm S.E.M. values for FSH and LH $(n=30)$ and oestradiol and progesterone $(n=15)$ in mares normalized to emergence of the future ovulatory follicle on the day it was closest to $13.0 \mathrm{~mm}$. The mean day of the beginning of deviation relative to emergence is based on the diameter closest to $22.7 \mathrm{~mm}$. An asterisk indicates changes $(P<0.05)$ on each side of emergence.

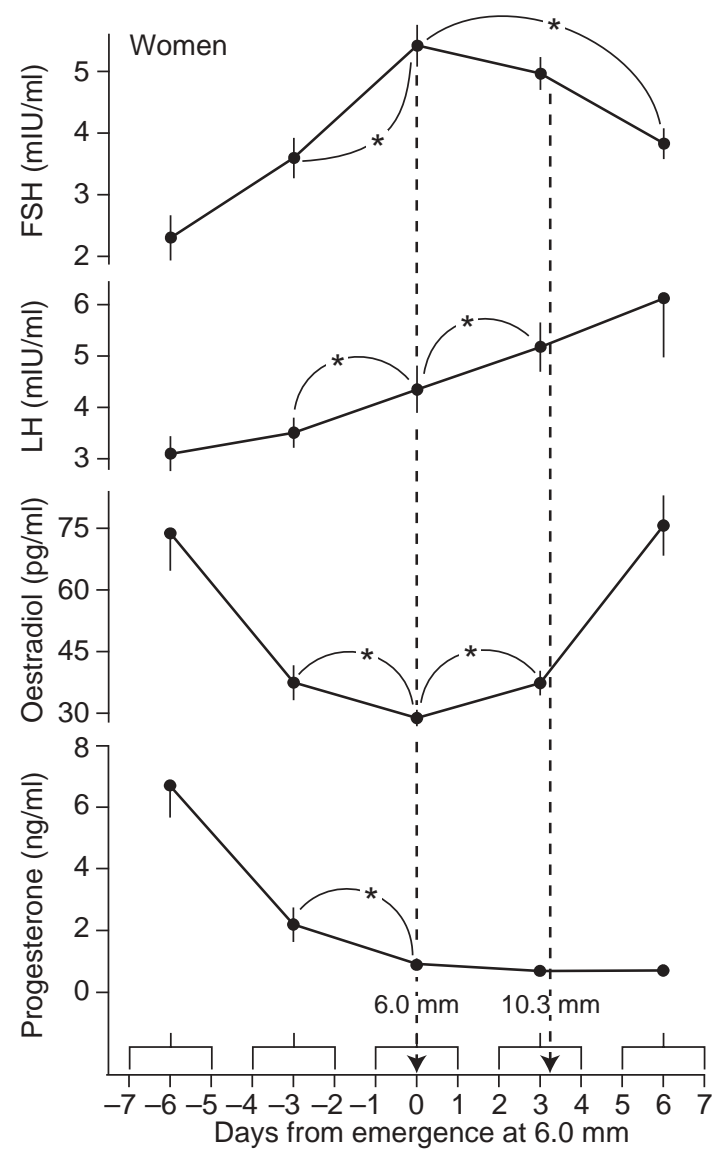

Figure 5 Mean \pm S.E.M. values for FSH, LH, oestradiol and progesterone in 30 women normalized to emergence of the future ovulatory follicle on the day it was closest to $6.0 \mathrm{~mm}$. The mean day of the beginning of deviation relative to emergence is based on the diameter closest to $10.3 \mathrm{~mm}$. An asterisk indicates changes $(P<0.05)$ on each side of emergence. 
$(P<0.0001$; Fig. 5). Concentrations of $\mathrm{LH}$ began to increase before emergence and continued to increase after emergence and deviation. Oestradiol decreased before emergence and increased after emergence and both further increased after the beginning of expected deviation. When daily values were used, both LH and oestradiol increased $(P<0.04)$ between 2 days $(\mathrm{LH}$, $3.6 \pm 0.7 \mathrm{mIU} / \mathrm{ml}$; oestradiol, $27.9 \pm 2.9 \mathrm{pg} / \mathrm{ml}$ ) and 1 day $(\mathrm{LH}, \quad 5.8 \pm 0.7 \mathrm{mlU} / \mathrm{ml} ; \quad$ oestradiol, $\quad 38.7 \pm 3.0 \mathrm{pg} / \mathrm{ml})$ before the beginning of deviation.

In mares, concentration of FSH on the day before expected deviation was negatively correlated with the number of growing follicles $(r,-0.39 ; P<0.04)$. Concentrations the day before deviation were greater $(P<0.006)$ in the group with one or two growing follicles $(16.4 \pm 1.7 \mathrm{ng} / \mathrm{ml} ; n=5)$ than in the group with three or more follicles $(10.9 \pm 0.7 \mathrm{ng} / \mathrm{ml} ; n=25)$. In women, the correlation on the day before deviation was negative $(r,-0.36)$ but was not significant; the FSH concentrations were greater for one and two follicles $(5.8 \pm 0.7 \mathrm{mlU} / \mathrm{ml})$ than for three or more follicles $(4.9 \pm 1.1 \mathrm{mlU} / \mathrm{ml})$ but the difference only approached significance $(P<0.1)$.

Concentrations of oestradiol in women during the luteal phase showed a day effect $(P<0.0001)$ from an increase $(P<0.001)$ between days $1-3$ and $7-9$ and a decrease $(P<0.0001)$ thereafter (Fig. 6). Luteal phases with minor follicular waves $(n=15)$ or major anovulatory waves $(n=5)$ were not different in oestradiol concentrations and were combined for comparison with luteal phases without anovulatory waves $(n=10)$. There were no differences between women with luteal-phase anovulatory waves versus no waves and no interaction of day by group.

\section{Discussion}

The temporal interrelationships among the circulating concentrations of the four hormones during the interovulatory

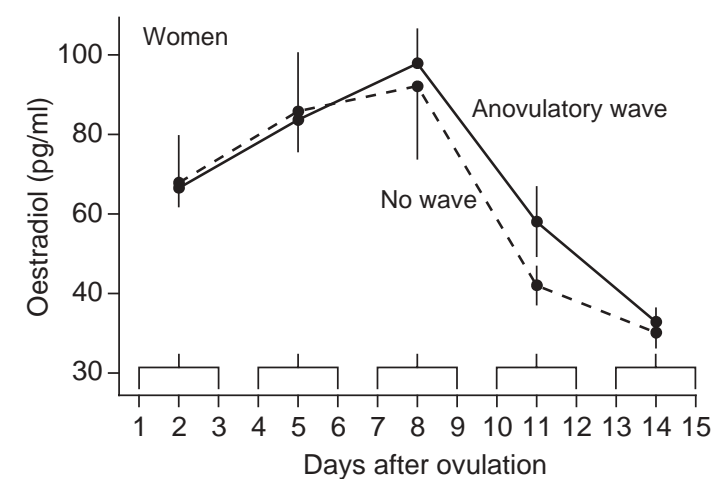

Figure 6 Mean \pm S.E.M. values for circulating oestradiol concentrations during the luteal phase in women. Data were grouped into women with an anovulatory wave $(n=20)$ and women with no anovulatory wave $(n=10)$. There were no significant differences between groups or a group-by-wave interaction. interval within mares and within women were consistent with previous descriptions for each species (see Introduction). The dissociated periovulatory relationships between $\mathrm{FSH}$ and $\mathrm{LH}$ in mares contrasts with the synchronized relationship between the two hormones at a comparable time in women. During the luteal phase and the follicular phase, mean FSH concentrations were high and low respectively in mares and low and high respectively in women. Mean FSH concentrations have been reported to be inversely related to mean inhibin concentrations throughout the interovulatory interval in mares (Bergfelt et al. 1991) and in women (Reddi et al. 1990). Thus, the two hormones are inversely related within each species, providing a temporal basis for a functional relationship between FSH and inhibin for each species. Moreover, concentrations of each hormone were reciprocally related between species, providing a strong comparative indication of the $\mathrm{FSH} / \mathrm{inhibin}$ relationship.

The high mean FSH concentrations during the luteal phase in mares was not representative of the concentrations in any individual mare. The high mean concentrations resulted from the averaging of the concentrations of FSH surges that occurred on different days and in different numbers in individuals. This relationship between group averages and individual mares is apparent also in published figures (Ginther 1992). As a reservation, statistical detection of an FSH surge was based on daily sampling and may account for the failure to detect expected surges in six mares. However, daily sampling has provided mean FSH concentration profiles that have been consistently compatible with the normalized time of emergence and deviation of follicular waves in published reports (for review see Ginther et al. 2003) and in this study. In addition, failure to detect some surges does not negate study of follicle/surge relationships in mares with identified surges. A surge was not detected after the ovulatory wave had emerged in $73 \%$ of the mares, accounting for the low mean concentrations of FSH in the later portion of the interovulatory interval.

The maximal mean FSH concentration in mares occurred on the day the future dominant follicle was closest to $13.0 \mathrm{~mm}$. Similarly, the diameter of the largest follicle at the peak of an identified FSH surge was $13.5 \mathrm{~mm}$ for ovulatory waves and a comparable $14.2 \mathrm{~mm}$ for anovulatory follicular waves. Deviation occurred during the FSH decline or approximately 3 days after emergence. These results confirmed previously reported findings for both the ovulatory (Gastal et al. 1997) and anovulatory (Donadeu \& Ginther 2003) seasons. However, the reported results were based on follicular waves and FSH surges that were induced by ablation of all follicles $\geq 6 \mathrm{~mm}$. The present findings are the first to demonstrate that the FSH/follicle diameter relationships are similar for natural waves as for previously reported induced waves.

In women, the periovulatory FSH surge was the source for the stimulation of a major anovulatory wave or a minor wave in four and 15 women respectively, based on 
temporal relationships. Women clearly differed from mares in the consistent prolonged suppression of $\mathrm{FSH}$ during the luteal phase. The luteal-phase FSH suppression is attributable to secretion of inhibin and oestradiol by the corpus luteum (Baird et al. 1975, Reddi et al. 1990). Thus, regression or experimental removal of the corpus luteum is followed by the development of follicles (Baird et al. 1984). The hypothesis that at least part of the circulating oestradiol during the luteal phase originates from major and minor anovulatory follicular waves was not supported in the present study. There is apparently no published in vitro or in vivo indication that the equine corpus luteum produces inhibin (Ginther 1992) which, in contrast to women, is compatible with the frequent occurrence of FSH surges during the luteal phase. There have been suggestions that the equine corpus luteum may cause a slight increase in oestradiol on about day 6 (Ginther 1992), but such an increase was not found in the present study.

In women, a significant increase in FSH occurred between days 11 and 12 near the end of the luteal phase in agreement with previous reports (Miro \& Aspinall 2004). The maximal mean FSH concentration was close to the mean day of emergence at $6.0 \mathrm{~mm}$ of the future dominant follicle. In the means, a prominent ending nadir occurred in association with the beginning of the preovulatory $\mathrm{FSH} / \mathrm{LH}$ surges. The prolonged nature of the $\mathrm{FSH}$ surge in women was indicated by the means. However, unlike the poor agreement between the means and values for individuals during the luteal phase in mares, the means in women well represented the FSH profiles in individuals. A consistent appearance of an FSH nadir near the end of the luteal phase followed by a nadir before the second ovulation in individuals despite the 3-day sampling interval indicated that the FSH surge was prolonged and uninterrupted. The prolonged (mean, 15 days) FSH elevation during the follicular phase represented the apparent stimulating surge for the ovulatory follicular wave.

The maximal mean FSH concentration in women occurred on the day the future dominant follicle was closest to $6.0 \mathrm{~mm}$. The diameters representing emergence for the two species were chosen solely on the basis of relative diameters between species during various follicle events during the ovulatory wave (Ginther et al. 2004b). The present $\mathrm{FSH}$ results have indicated that the diameter chosen for emergence within each species was related to the peak of the wave-stimulating FSH surge, supporting the corresponding hypothesis. In women, as in mares, deviation began 3 days after the FSH peak during the FSH decline. Similarity between the two species in relative changes in diameters of follicles of the natural ovulatory wave have been reported previously (Ginther et al. 2004b); in the present study, similarity between the two species in the temporal follicle/FSH relationships were found during the wave-stimulating $\mathrm{FSH}$ surge, except that the surge was more prolonged in women. Thus, mares may be a useful research model for women in studies involving the role of
FSH and mechanism of action during the early portion of an ovulatory wave encompassing both emergence and deviation.

In mares, LH concentrations from the first periovulatory surge were decreasing during the days when FSH concentrations of the wave-stimulating surge were increasing. A significant increase in LH concentrations in association with deviation was not found. Oestradiol remained at baseline concentrations during the days encompassing both emergence and deviation. These LH and oestradiol results conflict with the reports of increasing oestradiol and $\mathrm{LH}$ before deviation during follicular waves that were induced by ablation of follicles on day 10 (Gastal et al. 1997, 2000). However, the present finding that $\mathrm{LH}$ and oestradiol did not increase before natural deviation does not eliminate a role for basal levels of the hormones. Further study is needed. In contrast to mares, the concentrations of $\mathrm{LH}$ and oestradiol in women increased before the beginning of deviation. Thus, the hypothesis that $\mathrm{LH}$ and oestradiol increase before the beginning of deviation was supported for women but not for mares.

In mares, the FSH decrease after the peak concentrations has been attributed to inhibin, based on inverse temporal relationships between $\mathrm{FSH}$ and inhibin concentrations beginning after the peak of the surge during both the ovulatory and anovulatory seasons (Donadeu \& Ginther 2001, 2003). In addition, the extent of FSH decrease was related to the extent of inhibin increase in mares with manipulated numbers of follicles after the FSH peak (Donadeu \& Ginther 2001). The increase in oestradiol during the decrease in $\mathrm{FSH}$ in the present study in women is compatible with an oestradiol role in FSH suppression after the FSH peak. In this regard, previous studies have indicated that oestradiol is the likely $\mathrm{FSH}$ suppressor during the follicular phase; oestradiol increased whereas inhibin did not during the mid-follicular phase (Reddi et al. 1990), and passive immunization of rhesus monkeys with an anti-oestrogen during the midand late-follicular phase prevented the FSH decrease and increased the number of preovulatory follicles (Zeleznik et al. 1987). The result of anti-oestrogen treatment in primates is similar to the result of anti-inhibin treatment in mares (Briant et al. 2000). Thus, the present results, together with reported results, indicated that inhibin in mares and oestradiol in women are the primary postemergence suppressors of FSH.

Studies with induced waves and manipulation of follicle numbers in mares (Donadeu \& Ginther 2001) and cattle (Gibbons et al. 1997) have indicated that three or more follicles are needed to reduce FSH concentrations to the low concentrations characteristic of the day before deviation. Comparisons between $\mathrm{FSH}$ concentrations and the number of growing follicles for natural waves and surges on the day before deviation in the present study found a negative correlation that was similar for mares $(r$, -0.39) and women $(r,-0.36)$, but the correlation was significant only for the mares. Similarly, the difference in 
FSH concentrations between groups with one or two versus three or more follicles was significant in mares but only approached significance in women. It may be important that the number of individuals with blood samples on the day before deviation was smaller in women, owing to blood collection at 3-day intervals. Thus, the hypothesis that the number of growing follicles affects the extent of the predeviation decrease in FSH during natural follicular waves and FSH surges was supported for mares but results were inconclusive for women.

In conclusion, high mean concentrations of FSH during the luteal phase in mares resulted from the averaging of FSH concentrations from surges (mean duration, 4 days) that occurred on different days and in different numbers in individuals. In women, FSH was consistently depressed during the luteal phase. The hypothesis that anovulatory follicular waves contributed to the elevated oestradiol concentrations in women during the luteal phase was not supported. An apparently prolonged FSH surge (mean length, 15 days) began in women toward the end of the luteal phase and on a temporal basis gave rise to the ovulatory follicular wave. The number of growing follicles on the day before deviation influenced the extent of FSH suppression in mares but similar results only approached significance in women. Increasing concentrations of $\mathrm{LH}$ and oestradiol did not encompass the beginning of deviation in mares, but increases for both hormones began before deviation in women. The hypothesis that the mean peak of the wave-stimulating FSH surge occurred at the defined day of follicle emergence (mares, $13.0 \mathrm{~mm}$; women, $6.0 \mathrm{~mm}$ ) and deviation occurred during the decrease in FSH in both species was supported. These results indicated that mares would be a useful research model for the study of the role and mechanism of action of FSH during the early follicle events of the ovulatory wave in women.

\section{Acknowledgements}

This work (Project W2-OG-05) was supported by the Eutheria Foundation, Cross Plains, WI, USA, the Federal University of Viçosa, Brazil, and a grant from the Canadian Institutes of Health Research. The authors thank A F Parlow National Hormone \& Peptide Programe Harbor-UCLA Medical Center, Torrance, CA, USA, for gonadotrophin RIA reagents and S Jensen for assistance with hormone assays and statistical analyses. The authors declare that there is no conflict of interest that would prejudice the imparitiality of this scientific work.

\section{References}

Baerwald AR, Adams GP \& Pierson RA 2003 Characterization of ovarian follicular wave dynamics in women. Biology of Reproduction 69 1023-1031.

Baerwald AR, Adams GP \& Pierson RA 2005 Form and function of the corpus luteum during the human menstrual cycle. Journal of Ultrasound, Obstetrics and Gynecology 25 498-507.

Baird DT, Baker TG, McNatty KP \& Neal P 1975 Relationship between the secretion of the corpus luteum and the length of the follicular phase of the ovarian cycle. Journal of Reproduction and Fertility 45 611-619.

Baird DT, Backstrom T, NcNeilly AS, Smith SK \& Wathen CG 1984 Effect of enucleation of the corpus luteum at different stages of the luteal phase of the human menstrual cycle on subsequent follicular development. Journal of Reproduction and Fertility $\mathbf{7 0}$ 615-624.

Bergfelt DR, Mann BG, Schwartz NB \& Ginther OJ 1991 Circulating concentrations of immunoreactive inhibin and FSH during the estrous cycle of mares. Journal of Equine Veterinary Science $\mathbf{1 1}$ 319-322.

Briant C, Blanc M, Daels P \& Guillaume D 2000 Effect of passive and specific immunization against inhibin in pony mares. Theriogenology 53-54.

Donadeu FX \& Ginther OJ 2001 Effect of number and diameter of follicles on plasma concentrations of inhibin and FSH in mares. Reproduction 121 897-903.

Donadeu FX \& Ginther OJ 2002 Changes in concentrations of follicular-fluid factors during follicle selection in mares. Biology of Reproduction 66 1111-1118.

Donadeu FX \& Ginther OJ 2003 Interactions of follicular factors and season in the regulation of circulating concentrations of gonadotrophins in mares. Reproduction 125 743-750.

Fauser BCJM \& van Heusden AM 1997 Manipulation of human ovarian funcrtion: physiological concepts and clinical consequences. Endocrine Reviews 18 71-106.

Fitzgerald BP, I'Anson H, Legan SJ \& Loy RG 1985 Changes in patterns of luteinizing hormone secretion before and after the first ovulation in the postpartum mare. Biology of Reproduction 33 316-323.

Gastal EL, Gastal MO, Bergfelt DR \& Ginther OJ 1997 Role of diameter differences among follicles in selection of a future dominant follicle in mares. Biology of Reproduction 57 1320-1327.

Gastal EL, Gastal MO \& Ginther OJ 1999 Experimental assumption of dominance by a smaller follicle and associated hormonal changes in mares. Biology of Reproduction 61 724-730.

Gastal EL, Gastal MO, Nogueira GP, Bergfelt DR \& Ginther OJ 2000 Temporal interrelationships among luteolysis, FSH and LH concentrations and follicle deviation in mares. Theriogenology $\mathbf{5 3}$ 925-940.

Gibbons JR, Wiltbank MC \& Ginther OJ 1997 Functional interrelationships between follicles greater than $4 \mathrm{~mm}$ and the folliclestimulating hormone surge in heifers. Biology of Reproduction $\mathbf{5 7}$ 1066-1073.

Ginther OJ 1992 In Reproductive Biology of the Mare, Basic and Applied Aspects, edn 2, pp 233-256. Cross Plains, WI, USA: Equiservices Publishing.

Ginther OJ, Beg MA, Donadeu FX \& Bergfelt DR 2003 Mechanism of follicle deviation in monovular farm species. Animal Reproduction Science 78 239-257.

Ginther OJ, Beg MA, Gastal MO \& Gastal EL 2004a Follicle dynamics and selection in mares. Animal Reproduction 1 45-63.

Ginther OJ, Gastal EL, Gastal MO, Bergfelt DR, Baerwald AR \& Pierson RA 2004b Comparative study of the dynamics of follicular waves in mares and women. Biology of Reproduction $\mathbf{7 1}$ $1195-1201$

Haughian JM, Ginther OJ, Kot K \& Wiltbank MC 2004 Relationships between $\mathrm{FSH}$ patterns and follicle dynamics and the temporal associations among hormones in natural and $\mathrm{GnRH}$-induced gonadotropin surges in heifers. Reproduction 127 1-12.

Lin K-C \& Lee J-N 1998 Characterization of pulsatile secretion of gonadotropin and prolactin in women with normal menstrual cycle, secondary amenorrhea and polycystic ovary syndrome (PCOS). Kaohsiung Journal of Medical Science 14 61-67.

Miro F \& Aspinall LJ 2004 The onset of the initial rise in follicle-stimulating hormone during the human menstrual cycle. Human Reproduction 20 96-100.

Reddi K, Wickings EJ, McNeilly AS, Baird DT \& Hillier SG 1990 Circulating bioactive follicle stimulating hormone and immuno- 
reactive inhibin levels during the normal human menstrual cycle. Clinical Endocrinology 33 547-557.

van Santbrink EJP, Hop WC, van Dessel TJHM, de Jong FH \& Fauser BCJM 1995 Decremental follicle-stimulating hormone and dominant follicle development during the normal menstrual cycle. Fertility and Sterility 64 37-43.

Zeleznik AJ 2001 Follicle selection in primates: 'Many are called but few are chosen'. Biology of Reproduction 65 655-659.

Zeleznik AJ, Hutchison JS \& Schuler HM 1987 Passive immunization with anti-oestradiol antibodies during the luteal phase of the menstrual cycle potentiates the perimenopausal rise in serum gonadotrophin concentrations and stimulates follicle growth in the cynomolgus monkey. Journal of Reproduction and Fertility $\mathbf{8 0}$ $403-410$.

Received 15 April 2005

First decision 23 May 2005

Revised manuscript received 27 May 2005

Accepted 6 June 2005 